\title{
Rehousing a historical tintype photographs by designing a new preserving photographic album
}

\author{
"Elsayda-Nafesa El-Shamy \\ *Conservation Department, Faculty of Archaeology and Tourism Guidance, Misr \\ University of Science and Technology, Egypt.
}

\begin{abstract}
:
Photographic collections are found in libraries, archives and museums all over the world. Also private collections include large amounts of historical photographs, which can be a witness of our ancestors and their lifestyles as well as everything of artistic or human expressions. Thus the importance of preserving the historical photographs, especially the tintype photos the subject of the study due to its sensitive nature and the scarcity of presence. Their sensitivity to environmental conditions and the speed with which images can deteriorate present special challenges. Although photography had a profound social presence and influence in the last 150 years, the conservation of photographic objects has been developed relatively recently in the last 30 years. This study aims to approach and submit a re-housing preservation method to four of historical tintype private collection photographs dates back $1856-1860$ on blackened iron plates from California called "Bon-ton", ranged from $23 / 8$ in $\times 31 / 2$ in $(60 \mathrm{~mm} \times 89 \mathrm{~mm})$ to 4 in $\times 53 / 4$ in $(100 \mathrm{~mm} \times 150 \mathrm{~mm})$ by suggestion an AutoCAD design of archival acid-free mat boards in paper enclosures then in acid-free folding boxes, which permits good examination of the photographic objects while the board provides strong support and protection from ageing damage, mechanical-chemical deterioration, dirt, dust, and gaseous pollutants also reduces mechanical damage from frequent handling. In addition to allow a safer access to these valuable historical photographs for viewing or exhibiting. The purpose of the cataloguing is to preserve the photographic album as well as expand the accessibility of the photographs within the collection. The study also will address the aspects of housing the historical photographs through putting the albums structure criteria of housing historical photographic collections.
\end{abstract}

Key words: Re-housing - tintype - preserving - album - historical photographs

\section{Introduction:}

Photography is the process of using light to record images. The birth of photography occurred in the 19th Century (Jill, 2009). Photographic objects are composite items, typically composed of three layers: the support, which can be glass, metal or paper, or another; the emulsion, which comprises a binder and the image forming particles; and additional layers such as colour particles and finishing coatings (Roosa, 2004). Tintypes, or Ferrotypes first appeared in America in the 1850s, but didn't become popular in Britain until the 1870s (Edward, 1903). Tintypes, or ferrotypes, are also direct positives. They are positive wet collodion images on a metal 
support coated with a black varnished layer on which the emulsion was applied. The first mention of the process was in 1855, by the French photographer Adolphe A. Martin, but had little impact. the process was also patented in England by William Kloen and Daniel Jones. The technique is virtually the same as for the ambrotypes, but with a metal plate as support (Osterman and Romer, 2007). A tintype, also known as a melainotype or ferrotype, is a photograph made by creating a direct positive on a thin sheet of metal coated with a dark lacquer or enamel and used as the support for the photographic emulsion. Tintypes became so popular that they turned into a mass production industrial product: the plates were produced in factories and sold to the photographers already coated on both sides (Kasher, 2008).

Tintypes, also known as ferrotypes, are the 19th century's "instant" photographs. Historically, "wet-plate" tintypes, containing silver halide in a collodion suspension, came first. They were made obsolete by "dry-plate" tintypes that used gelatin instead of flammable collodion. Dry-plate tintypes were coated on steel that was painted black and sometimes on black paper or cardboard. (The "tin" in tintypes comes from the similarity of the metal plates to the steel used in "tin" cans.) The Tintype Parlor produces authentic dry-plate tintypes. According to manuals of the time, developers used in tintypes included: ferrous sulphate, sugar and lead nitrate; ferrous sulphate, potassium nitrate, acetic acid and alcohol; ferrous sulphate and barium nitrate; pyrogallic acid, nitric acid and alcohol; sulphite of soda, carbonate of potash, ammonium bromide, hydroquinone, potassium carbonate, sodium sulphite, glycine and hypo. The finishing varnishes were similar to those used in ambrotypes, such as copal, sandarac, dammar and amber. The tintype was the easiest and cheapest photographic process at the time, because iron plates were less expensive than sheets of glass. They were also more resistant, so they could be easily transported sent through the mail, thus the occasional term letter types for them. Both these factors contributed to the commercial success of the product, making it the most popular photographic technique in the USA between 1865 and 1900 (Duchochois, 1891; Klein, 1905; Teresa and Catarina, 2016). Alternatively, these large plates could be used in multiplying cameras, obtaining multiple images in one plate, which were then cut into individual images. This resulted in sharp and irregular edges, which the photographers clipped. Finally, vignetting was popular technique used in tintypes and other processes, which consisted in gradually fading the edges of the image. In tintypes, it was done by placing a mask in front of the lens. In the $1880 \mathrm{~s}$, dry gelatine tintypes were introduced. These were sold already sensitized and ready to use (Eastabrooke, 1880).

Photography is different. It needs the special kind of care and attention. Housing process is considered an important step that affects the photographic object not only as protection, but also facilitate accessibility, interpretation of the object and be adapted to fit the needs of each specific collection, depending on how the photographs are intended to be used. Espically in the historical albums. The album's functionality as a container for photographs subjects it to protect the photos from physical and chemical 
degradation due to frequent handling, improper storage and poor production material, which then cause the structure's failure to preserve the prints (Lozano, 2007).

Early ferrotypes were presented in the same style of protective cases used for daguerreotypes and ambrotypes. Around 1863 and until 1866, they were presented in paper mats. They could also put in frames, which were used between 1865 and the early 1870 s, and passe-partouts. The formats were variable, because they could be made in any size. Regarding the exposure, tintypes require a very specific light, about the double amount than what is required for other negatives, otherwise the image is dull and smoky. The manuals also mention metallic stains on plates, a problem encountered on tintypes. These are composed of metallic silver transformed from the silver nitrate by some agent (Reilly, 1986; Trask, 1872).

This study explores designing a new digital method (an AutoCAD 2018 design version 22.0 DWG tag AC1032 from Autodesk) of re-housing for four historical photos (private collection dating from California through the $1860 \mathrm{~s}$ ) on blackened iron plates from California called "Bon-ton", ranged from $23 / 8$ in $\times 31 / 2$ in $(60 \mathrm{~mm} \times 89 \mathrm{~mm})$ to 4 in $\times 53 / 4$ in $(100 \mathrm{~mm} \times 150 \mathrm{~mm})$ in paper enclosures then in acid-free folding boxes. This new re-housing method preserves these historical tintype photos and prevents them from ageing deterioration factors and presents a preservation handling method. Besides the study explain the aspects of housing the historical photographic collections criteria and albums structure.

\section{Materials and methods:}

A preservation strategy has played a vital role in caring and protecting the photographic materials. Considering the many issues pertaining to format and type, condition, housing, value, access, and use, including albums, scrapbooks, and newer items such as microforms. However, boxes and groups of items can be randomly sampled and assessed for storage, treatment, handling, and exhibition needs. Archives need to be stored in conditions which are cool, dry and seasonally stable, with minimum exposure to natural or artificial light and protection from pests, pollution and access by unauthorized people. Poor storage conditions can also put archives at risk. Providing good storage conditions slows down deterioration over time and helps to prevent damage from dirt, mold or pests. High temperatures and high relative humidity speed up chemical changes in from the materials stored in your archive. This speeds up degradation. Photographs and film benefit from storage at a lower relative humidity of 30-35\% (Helen, 2016).

If the photographic materials, housing is damaged it should be rehoused in acidfree archival sleeves or paper enclosures and folders to prevent damage from chemical deterioration and improper handling them in acid-free folding boxes or in cabinets with neutral $\mathrm{pH}$ tissue to protect them from dirt, dust, and gaseous pollutants and for tintypes photographic materials it is should be identify actively deteriorating cover glasses and replace them with contemporary high-grade alumina silicate glass. Also place humidity indicator strips within the bag to help monitor environmental conditions. Tintype original housing should consider as a total artifact deserving protection as a whole. 
Don't disturb these housings unless absolutely necessary. Then Write the catalog number and other identifying information in pencil on the outside of the box. If possible, use acrylic adhesive on $3 \mathrm{M}$ mounting tape to adhere a $35 \mathrm{~mm}$ contact print of the image to the outside of the storage box to help minimize handling of these fragile artifacts. House loose tintypes in good-quality paper or plastic, such as polyester and polypropylene film, enclosures. Four-ply ragboard inserted behind the tintype will provide its flexible support with additional protection. House sleeved tintypes vertically in acidfree boxes (never in plastic enclosures) (Albright, 1993; Hendriks, 1989).

The first step before re-housing is to create a digitalized documentation of the current condition and the photographic arrangement to help maintain the preservation of the intellectual order of the album. The album is housed in an acid-free Hollinger box with ethafoam sheets to keep it stable, the purpose of the cataloguing is to preserve the photographic album as well as expand accessibility of the photographs within the collection (Melodie, 2012). The study applied these steps on the four historical tintype photographs by a new digital method (an AutoCAD 2018 design version 22.0 DWG tag AC1032 from Autodesk) of re-housing as the following:

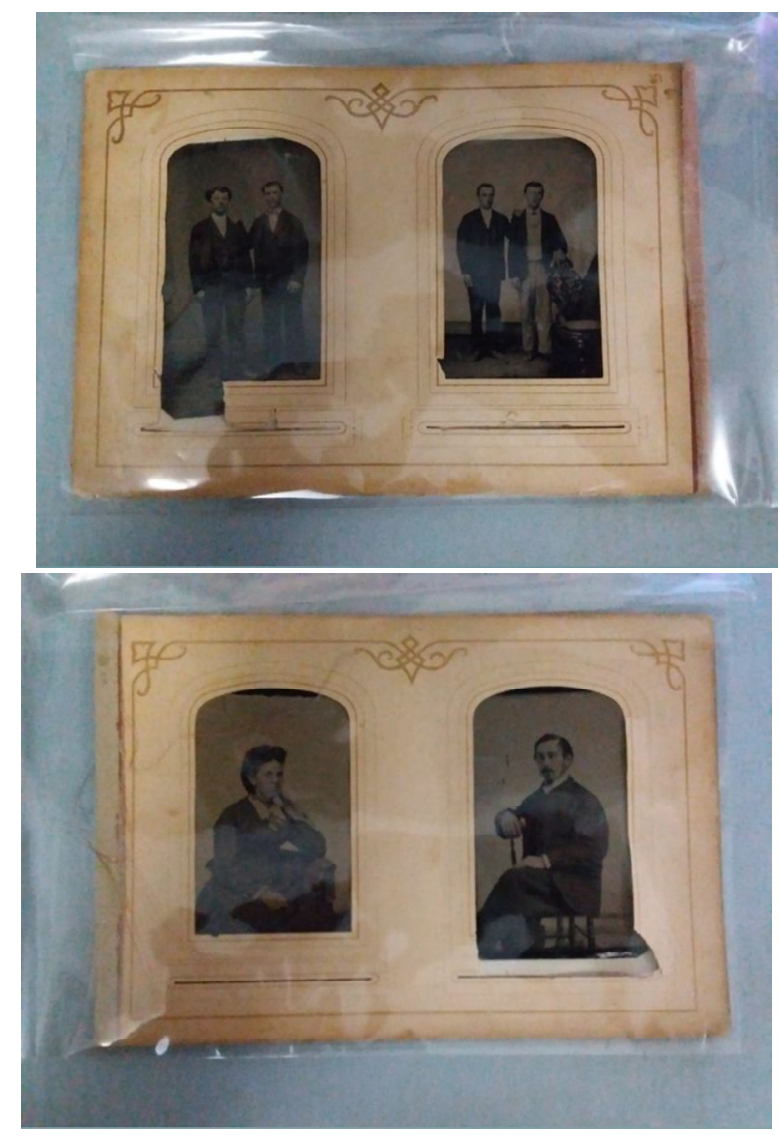

Fig. 1. Various photographs from private collection: four historical tintype photographs dates back 1856

-1860 on blackened iron plates from California called "Bon-ton", ranged from 238 in $\times 31 / 2$ in $(60 \mathrm{~mm} \times 89 \mathrm{~mm})$ to $4 \mathrm{in} \times 53.4 \mathrm{in}(100 \mathrm{~mm} \times 150 \mathrm{~mm})$ preserved in deteriorated old album. 

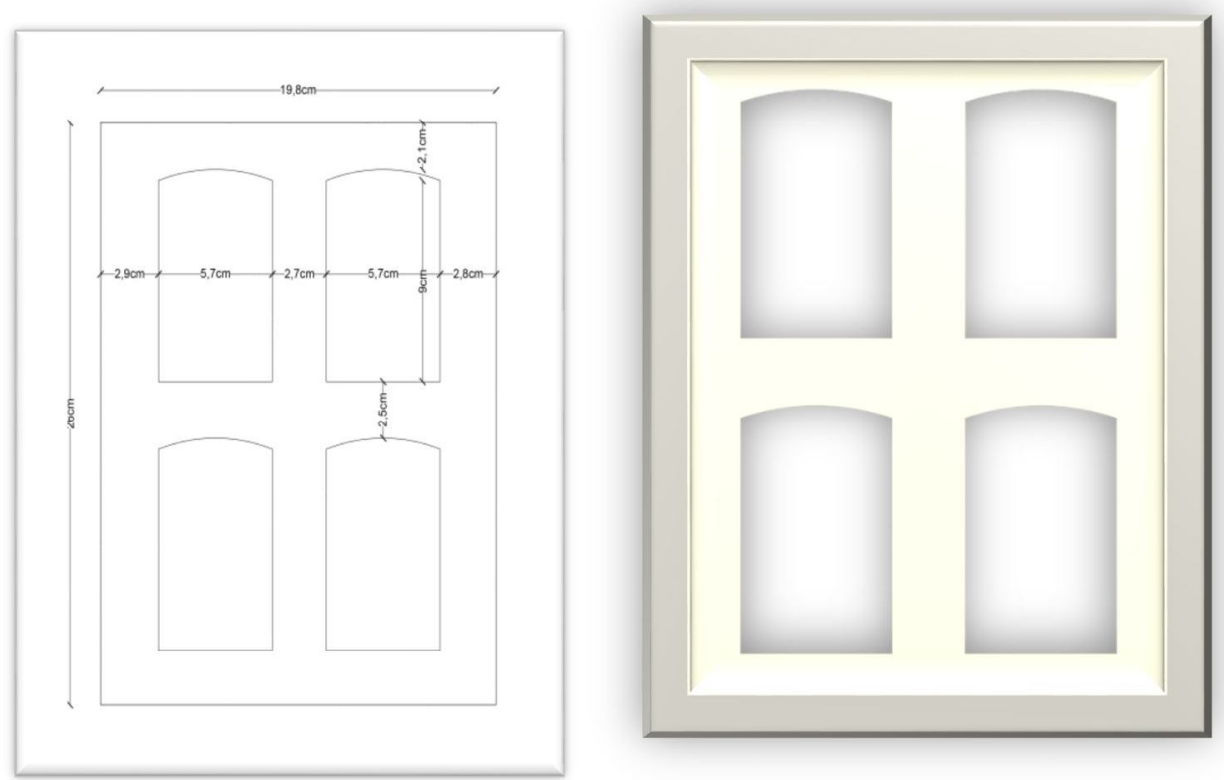

Fig.2. Process of constructing designing a new back mats: Small rectangle $3 / 4$ layout design template of photos created on InDesign next to the corresponding mat for display of the four photograph's verso which have marks and/ or inscriptions.
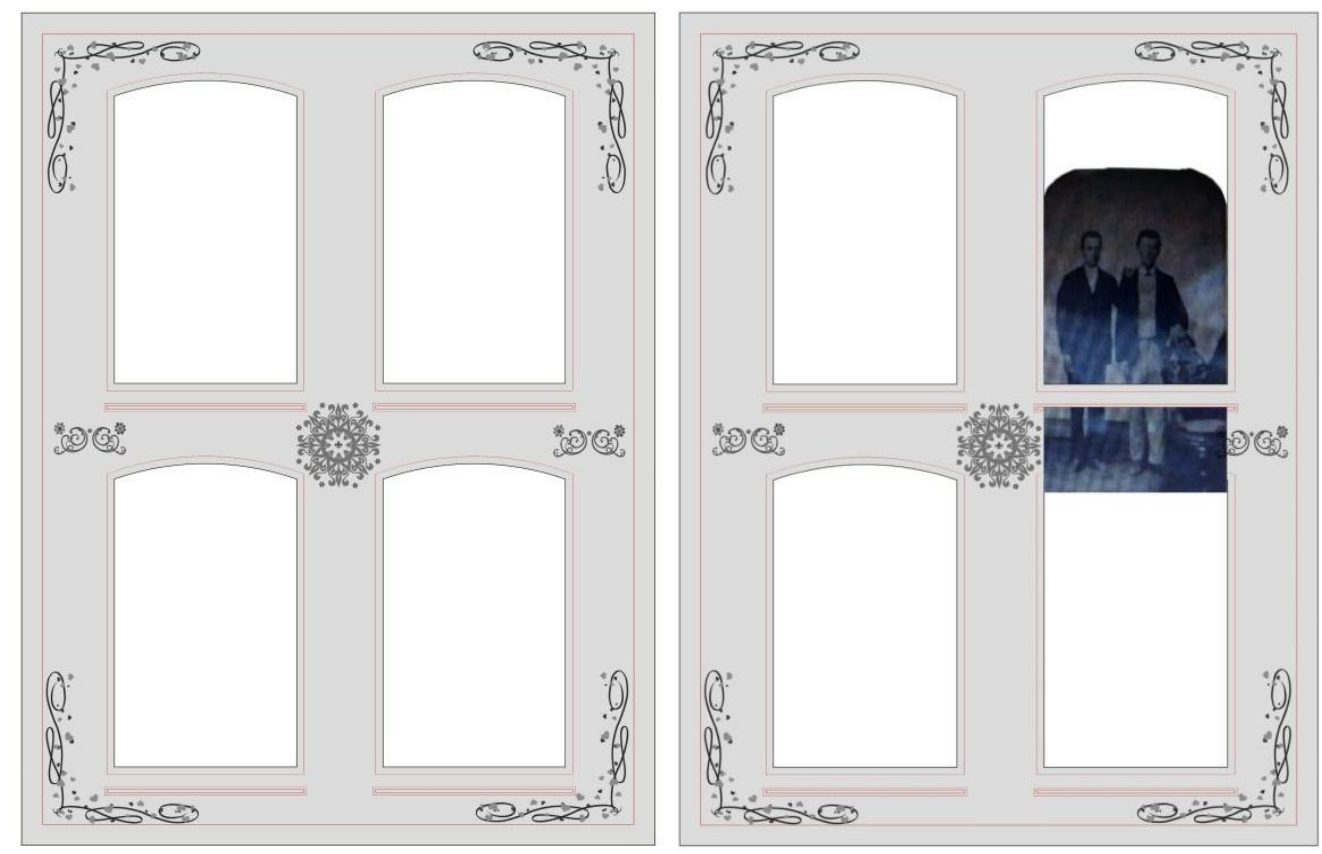

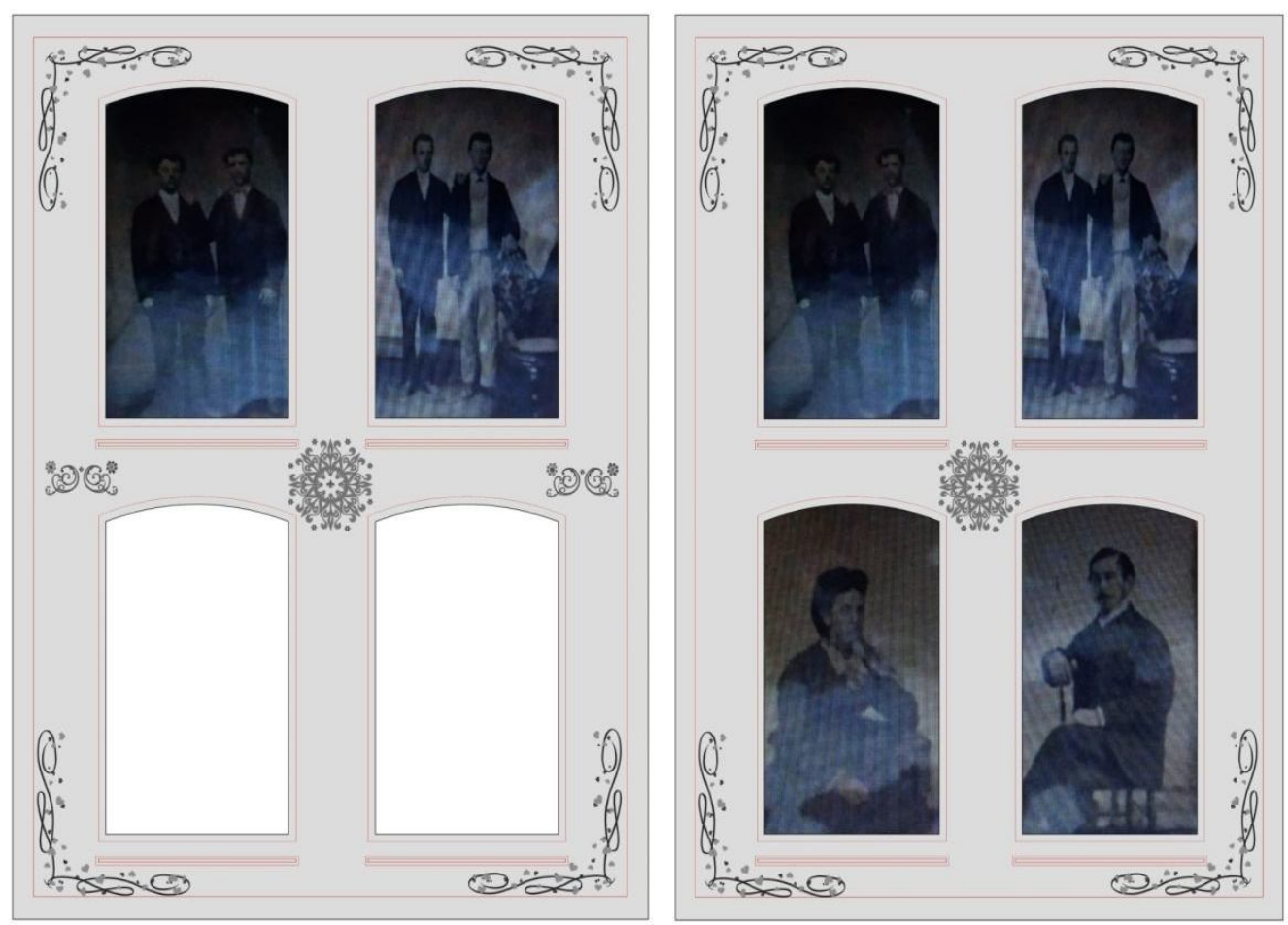

Fig.3. Facsimile constructing by AutoCAD mock-up archival four carte-de-visite layout page Which is made of a surrogated print from the scanned of the historical albums pages that has been digitally restored using PhotoShop and inserting the tintype photos into the album using AutoCAD and PhotoShop. 

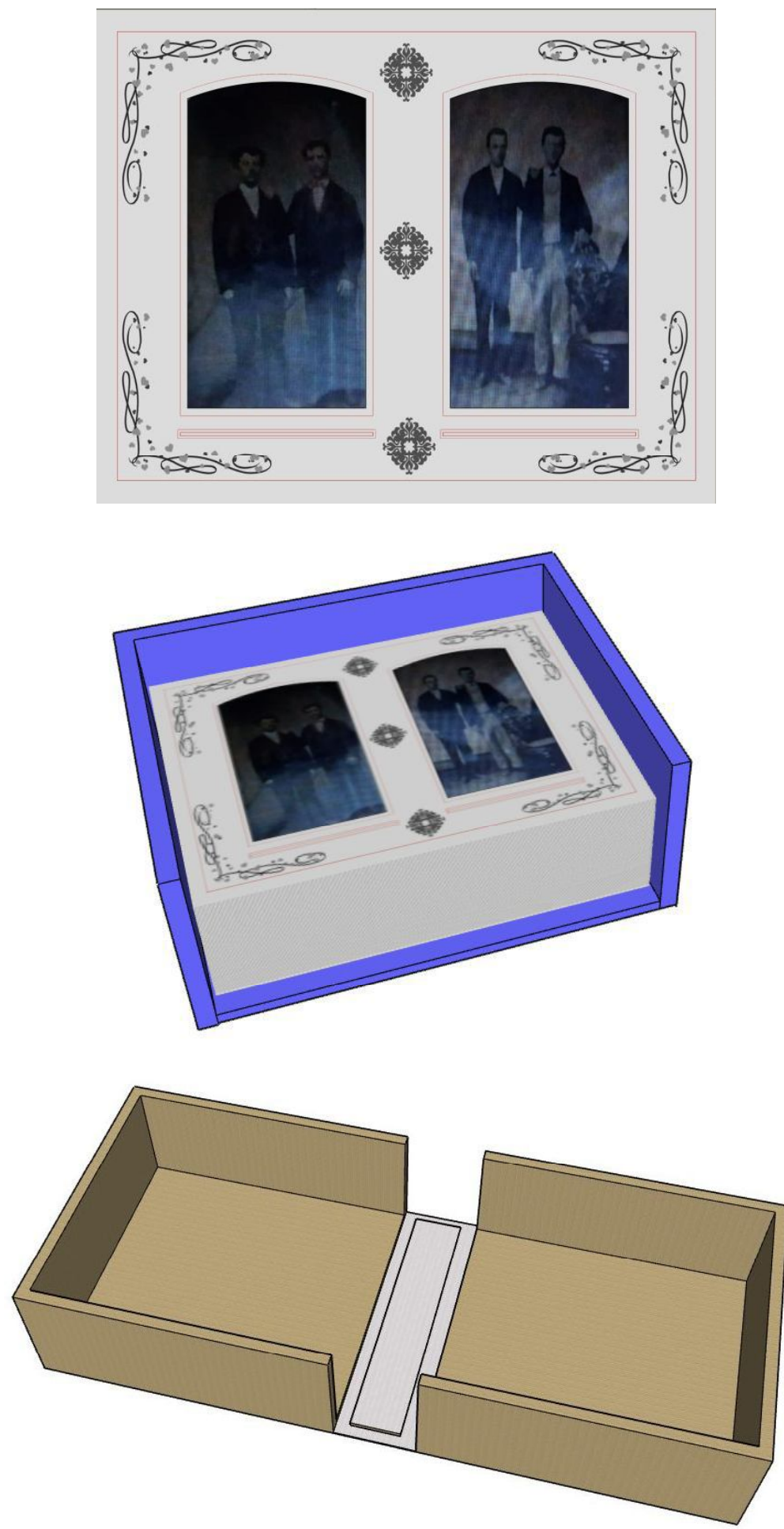

Fig.4. The final form of the historical tintype rehoused facsimile album: an AutoCAD design of archival acid-free mat boards in paper enclosures then in acid-free folding boxes

The aspects and criteria of housing the historical tintype photographs that should be taken into consideration:

Proper storage and enclosures for photographic materials are important preventive measures that protect items from physical damage, stabilize delicate or 
fragile materials, and provide basic care for all photographic materials in the collection. A number of factors influence storage decisions - condition of the photographs, frequency of use, space, environmental conditions, and staff and financial resources available. Many commercially available enclosures are labeled 'archival' or 'acid-free'. However, some of these same items may contain lignin, dyes, sizing agents, coatings, plasticizers, or other harmful additives.

- Never use enclosures made from unprocessed wood pulp paper, glassine, or polyvinyl chloride (PVC) to house or store photographs.

- Avoid products made from colored papers because they often contain dyes or inks that are unstable and will migrate or bleed onto photographs or otherwise adversely affect the photographs stored within. For an enclosure material to be completely safe it must meet or exceed the specifications in the latest revision of ISO 18902 including the Photographic Activity Test (PAT) ISO 18916.

Paper envelopes are often used to store prints and negatives. A good approach to housing photographs is to provide several layers of protection by first placing photographs into sleeves or envelopes, then into folders, and finally into document storage boxes. Paper enclosures usually cost less than plastic, but items that are used frequently can be abraded by repeated removal from and insertion into paper enclosures.

- Paper sleeves and envelopes should be made according to ISO specifications, which recommend that the paper have an alpha cellulose content of $87 \%$ and contain no lignin, ground wood, or alum-rosin sizing. The paper should be buffered to a $\mathrm{pH}$ of $7-9.5$.

Plastic enclosures are preferred for frequently used collections because they protect photographs from fingerprints and provide physical support.

- Plastic enclosures should be made from plastics such as polyester, polyethylene, polypropylene, spun-bonded polyolefin, or polystyrene. These plastics are recommended by ISO standards because they are typically inert, plasticized, and have good chemical stability.

- Avoid all plastics that have fillers, coatings, or UV absorbers. Avoid the use of polyester, polyethylene, and polypropylene that has a hazy film on the surface, which indicates that the plastic film is coated or is heavily plasticized. Avoid using adhesives or fasteners that may cause chemical or physical damage, such as rubber cement, pressure-sensitive tape, paper clips, or rubber bands. When not stored in cold conditions, plastic enclosures of any kind should not be used with nitrate or early acetate films.

Many adhesives used to mount photographs into albums and scrapbooks are acidic and will eventually discolor, become brittle, and damage materials. Albums can be wrapped in paper and placed in a document box or in a fitted protective enclosure.

Carelessness includes rough handling during cataloging, housing, and viewing; storage in a hazardous location; and damage to materials as a result of inadequate transport systems. Hands should be freshly washed, wear clean lint-free cotton gloves or inert plastic gloves (such as nitrile), and avoid touching the photograph surface. 
- Use a stable, appropriately sized book cart with horizontal shelves to transfer materials between storage and research areas

- Handle photographs with clean hands and avoid touching the image layer. Wearing clean, lint-free cotton gloves lessens the possibility of leaving fingerprints and soiling the materials.

- Support photographs carefully with both hands or, especially for larger and fragile photographs, slide a piece of paper or card underneath to act as a carrier.

- Keep food and drink away from photographs.

- Avoid marking photographs with ink. If necessary write lightly with a HB pencil on the reverse of the image.

- Keep historical photographs in folders or pockets to protect them from dust and light and provide physical support during use. Chemically stable plastic or paper folders or pockets, free of sulphur, acids, and peroxides, are recommended.

- Store film-based negatives (single sheets or strips cut into lengths of 4-6 frames) separately from other photographic materials, as they can produce acidic gases as they age.

- Keep cased items, such as tintype, in their original cases or frames. Wrap them in acid-free or photographic storage paper to reduce wear and tear on fragile cases.

- Preserve old photograph albums intact, storing them flat, preferably in acid-free or photographic conservation board boxes. They serve a dual purpose of organizing groups of images while protecting them from physical and environmental damage, and can be wonderful sources of historic and genealogical information.

- Check stored boxes of photographs from time to time to make sure that they are free of dust, dirt and insects (Mark, 2010; Susie, 2010; Mark, 2002; Bogvad, 1996; Robb, 1994; Roy, 1994; Reilly, 1986; Kenneth, 1975).

\section{Results and discussion:}

Maintenance of a stable storage environment is crucial to the longevity of photographic materials. The environmental factors that affect the preservation of photographic materials are relative humidity $(\mathrm{RH})$; temperature; air quality; light; biological agents; and handling and housekeeping practices. These factors are often interrelated. Ignorance, neglect, and carelessness account for a significant percentage of damage to photographs. Hence this study suggest a new re-housing methods of preserving historical tintype photographs which used and applied for the tintype for the first time and applied in the study by using AutoCAD. This method prevents them from ageing deterioration factors and presents a preservation handling method. Besides the study explain the aspects of housing the historical photographic collections criteria and albums structure.

\section{References:}

- Albright, Gary. "Storage Enclosures for Photographic Prints and Negatives," NPS Conserve O Gram 14/2. Washington, DC: National Park Service, 1993. 
- Bogvad Kejser, U. and M. S. Koch, eds. 1996. Research Techniques in Photographic Conservation: Proceedings of the Copenhagen Conference 1995. Copenhagen: Royal Danish Academy of Fine Arts.

- Duchochois, P. C. The Photographic Image: a theoretical and practical treatise, New York: Press of William R. Jenkins, 1891.

- Eastabrooke, E. M. The Ferrotype and How to Make it, New York: The Antony and Scovill Company, 1880.

- Edward M. Estabrooke, The Ferrotype and How to Make It, No. 69, 1903, p. 12.

- Helen Ford, Archive Principles and Practice: an introduction to archives for nonarchivists, the national archives, 2016, pp.213-220.

- Hendriks, Klaus. "The Stability and Preservation of Recorded Images," Imaging Processes and Materials,Neblette's Eighth Edition. New York, NY: Van Nostrand Reinhold, 1989.

- Jill K. Flowers, 19th Century Photograph Preservation, A Study of Daguerreotype and Collodion, University of Oklahoma preservation of information materials, 2009, pp. 1-3.

- Kasher, S.America and the Tintype, New York: International Center of Photography, 2008.

- Kenneth W. Duckett, Modern Manuscripts: A Practical Manual for Their Management, Care, and Use (Nashville: American Association for State and Local History, 1975): 5. 195-198.

- Klein, H. O. Collodion Emulsion, London: Penrose \& Co., 1905.

- Lozano, Gustavo "History and Conservation of Albums and Photographically Illustrated Books." Andrew W. Mellon Advanced Residency Program in Photograph Conservation Research, George Eastman House, 2007: 1-2.

- Mark A., Caring for your collections: photographic collections, State Library of Queensland, Cultural Centre, Stanley Place, 2010, pp.1-18 (www.slq.qld.gov.au)

- Mark Roosa, Care, handling, and storage of photographs, library of Congress, 2002, pp.2-6.

- Melodie Hueber, Housing the family: Re-housing the Peterkin Family (THERESA BYWATER PETERKIN) Carte-de-visite and Cabinet Portrait Album at the art gallery of Ontario, Ryerson University, 2012, pp.9-27.

- Osterman M.and G. B. Romer, "History and the Evolution of Photography," in The Focal Encyclopedia of Photography: Digital Imaging, Theory and Applications, History and Science, M. R. Peres, Ed., Oxford, Elsevier, 2007, pp. 23-177.

- Reilly, J. M. Care and Identification of 19th century photographic prints, Rochester: Eastman Kodak Company, 1986.

- Robb, Andrew and Monique Fischer. 1994. 'Guidelines for Care and Identification of Film-Base Photographic Materials' in Topics in Photographic Preservation, vol. 5. Washington: American Institute for Conservation Photographic Materials Group.

- Roosa, M. "Care, Handling, and Storage of Photographs," International Preservation Issues, vol. 5, 2004.

- Roy, Ashok and Perry Smith, eds. 1994. Preventive Conservation: Practice Theory and Research. London: International Institute for Conservation.

- Susie Clark, caring for your photographs, the national archives, The Institute of Paper Conservation, 2010, pp.50-58.

- Teresa F., and Catarina M., Morphological and chemical characterization of tintypes and ambrotypes, Évora, September 2016, pp.11-77.

- Trask, A. K. P. Practical Ferrotyper, Philadelphia: Benerman \& Wilson, 1872. 